Brit. J. industr. Med., 1947, 4, 223.

\title{
THE EXPERIMENTAL PRODUCTION OF X-RAY SHADOWS IN THE LUNGS BY INHALATION OF INDUSTRIAL DUSTS : I. IRON OXIDE
}

\author{
BY \\ H. E. HARDING, J. L. A. GROUT, and T. A. LLOYD DAVIES \\ From the Department of Pathology, Sheffield University; the Royal Sheffield Infirmary and Hospital; and the \\ Industrial Health Unit, Boots Pure Drug Co., Nottingham
}

(RECEIVED FOR PUBLICATION, NOVEMBER 15, 1946)

Our endeavour is to obtain a better understanding of the cause of radiographic shadows following the inhalation of industrial dusts, and to correlate the radiological and histological findings. This paper describes attempts to produce similar changes in the lungs of animals from inhalation of one such dust.

Harding (1945) showed that iron oxide, suspended in saline and injected into the tracheas of rats, results in radiographic shadows in the lungs similar to those occurring in siderosis in man, and that these shadows are due solely to iron oxide. Such a technique is highly artificial and bears very little relation to the inhalation of dust into the lungs under industrial conditions : it is even conceivable that the reactions in the lungs might be different under the two circumstances. In the present series of experiments an attempt is being made to reproduce as nearly as possible the atmospheric conditions occurring in industry.

\section{Material}

Our intention was to use " rouge," which is nearly pure $\mathrm{Fe}_{2} \mathrm{O}_{3}$, but when this material is stirred electrostatic phenomena result in its aggregation into rock-like lumps so that it is impossible to produce a cloud of dust. We were therefore driven to use " crocus," a less pure form of iron oxide. Both of these dusts are, however, used by silver polishers (McLaughlin and others, 1945). Analysis of the crocus used showed its percentage composition to be $\mathrm{Fe}_{2} \mathrm{O}_{3}, 81.5 ; \mathrm{Na}, \mathrm{Ca}, \mathrm{Mg}, \mathrm{K}$, all above 1 and below 3, As 0.012, $\mathrm{Pb} \mathrm{0.01,} \mathrm{Cu} \mathrm{0.003,} \mathrm{Mn}$ 0.003 , Ni 0.01 , total silica 0.6 , free silica 0.2 .

\section{Method}

Twelve rats, 2 months old, average weight $128 \mathrm{~g}$., were exposed to inhalation of dust in the animal chamber and dust feed apparatus previously described (Lloyd Davies, 1946). Exposure was continued for 3 hours daily for 140 days : the average dust count in the chamber was maintained at 1,500 to 2,000 particles per ml. for 16 days, then increased to 2,500 to 3,000 for 47 days, and finally increased to 5,000 particles per $\mathrm{ml}$. for 77 days. The differential count showed that 88 per cent. of the particles were $1 \mu$ or less in diameter.

Two animals appeared ill during the experiment and were killed; subsequently animals were sacrificed at intervals from $\mathbf{8 0}$ days to 235 days following cessation of exposure. The animals were anæsthetized with ether, the trachea exposed and ligated, and the animals killed by cutting the abdominal aorta (through an incision previously made in the abdominal wall). The lungs were subsequently removed in an inflated condition, and preserved in formol saline. After being radiographed, the lungs were examined histologically. Portions of several lobes were fixed for a further period in a saturated aqueous solution of corrosive sublimate, and sections were stained with hæmatoxylin and eosin, Weigert's elastin stain and van Gieson, and by Wilder's modification of Foot's method for reticulin fibrils : a few sections were also stained with potassium ferrocyanide and $\mathrm{HCl}$, and a few were examined after incineration at $500^{\circ} \mathrm{C}$. There were no essential differences in the lungs of animals killed at the varying intervals after exposure, and, in order to avoid repetition and because they afforded the longest opportunity for the development of a permanent tissue reaction, only the lungs of the three animals killed 235 days after the period of exposure are described here. No animals were kept for longer periods because of the risk of development of "spontaneous" bronchiectasis.

\section{Morbid Anatomy}

There was a fairly considerable variation in the amount of dust in the lungs of different animals sacrificed at the same period. There is no reliable method of measuring the degree of this difference, which we have noticed also with other dusts, but it may well be of the order of 100 per cent. Because of this animal variation, which is a marked but 
insufficiently recognized feature in human pathology, and because of the small number of animals involved, we do not place much weight on the impression that the quantity of dust present became steadily less as the period after exposure lengthened. None of the animals showed as great a concentration of dust in the lungs as is found in the organs of many industrial workers, and we are taking steps to increase the total quantity inhaled in future experiments. Nevertheless, a sufficient quantity was present to be clearly visible to the naked eye and to show the nature of the response in the lungs.

In the lungs of the 3 animals sacrificed after the longest period, iron oxide was clearly visible as tiny red spots that appeared to be mainly in the pleura but were also clearly visible within the lung substance. The hilar lymph glands appeared free from iron oxide. Sections showed that the pigment was contained within phagocytic cells that occurred mainly in aggregates at lymph junctions. Some of these aggregates were in the pleura, but the majority were related to small blood vessels a short distance below the surface of the lung (fig. 1, p. 232). Very few cells containing pigment were found in alveolar walls or alveolar spaces, and the lymphoid tissue around the bronchi contained only occasional cells of this type. Nowhere within the lung was there any evidence of reaction to the presence of these dust-filled phagocytes (figs. 2 and 3, p. 232). The number and thickness of reticulin fibrils appeared equal in the areas of lymph junction which contained many or no phagocytes : there was no trace of collagen fibre production, and elastic fibrils were unaltered.

\section{Radiography}

The radiographs (fig. 4, p. 232) showed pin-point dense shadows located at the periphery of the lung field and corresponding with small collections of iron oxide either in the pleura or just beneath the surface of the lung. No intensification of the lung markings was apparent.

\section{Discussion and Summary}

Definite radiological shadows have been obtained from the lungs of rats after inhalation of crocus, a crude form of $\mathrm{Fe}_{2} \mathrm{O}_{3}$. These shadows correspond exactly with aggregates of phagocytes containing dust. There is no evident tissue reaction to the presence of these phagocytes and their contained dust. The radiographic shadows are produced solely by the aggregates of iron oxide.

It is a pleasure to acknowledge the cheerful work of Miss $\mathrm{E}$. Wilkinson in the tedious task of attending the apparatus and recording the dust counts. The photomicrographs were taken by Mr. A. W. Collins, F.I.M.L.T.

\section{REFERENCES}

Harding, H. E. (1945), Brit. J industr. Med, 2,32

Lloyd Davies, T. A. (1946). Ibid., 3, 111. McLaughlin, A. I. G., Grout, J. L. A., Barrie, H. J., and Harding
H. E. (1945). Lancet, 1, 337. 


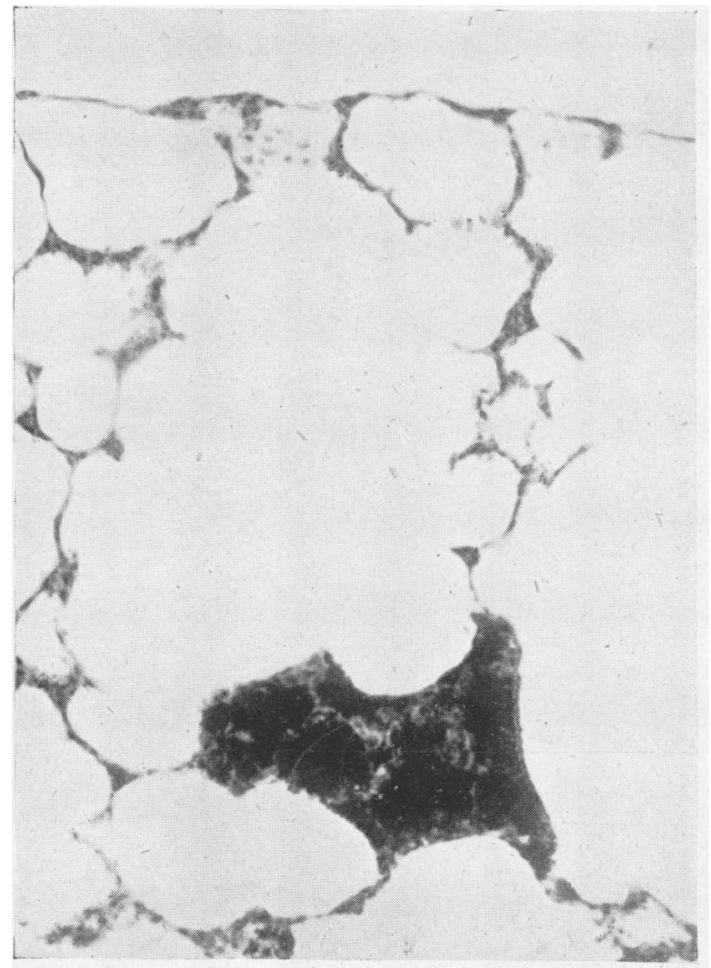

FIG. 1.

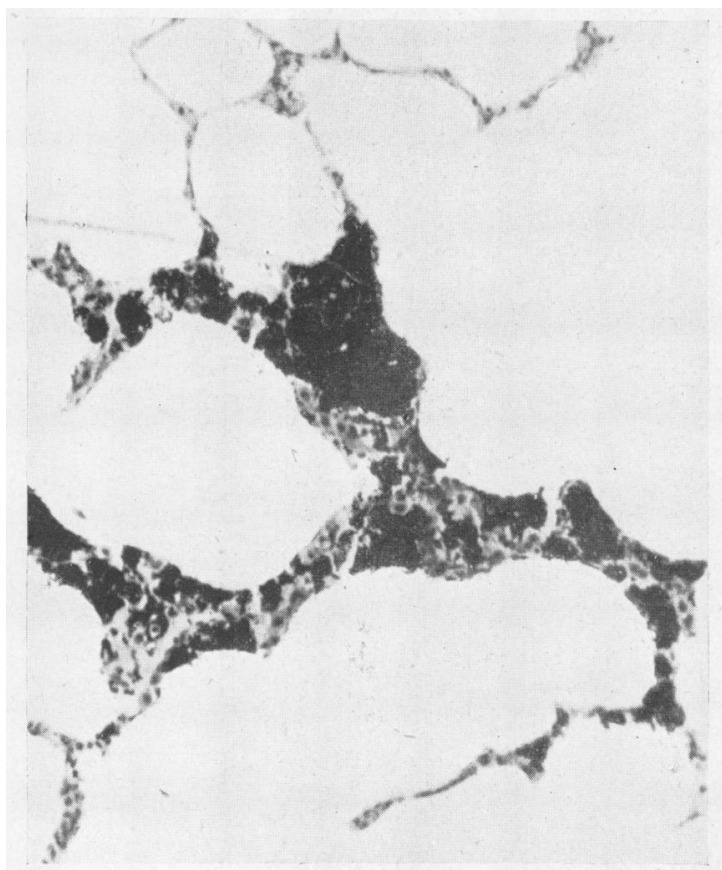

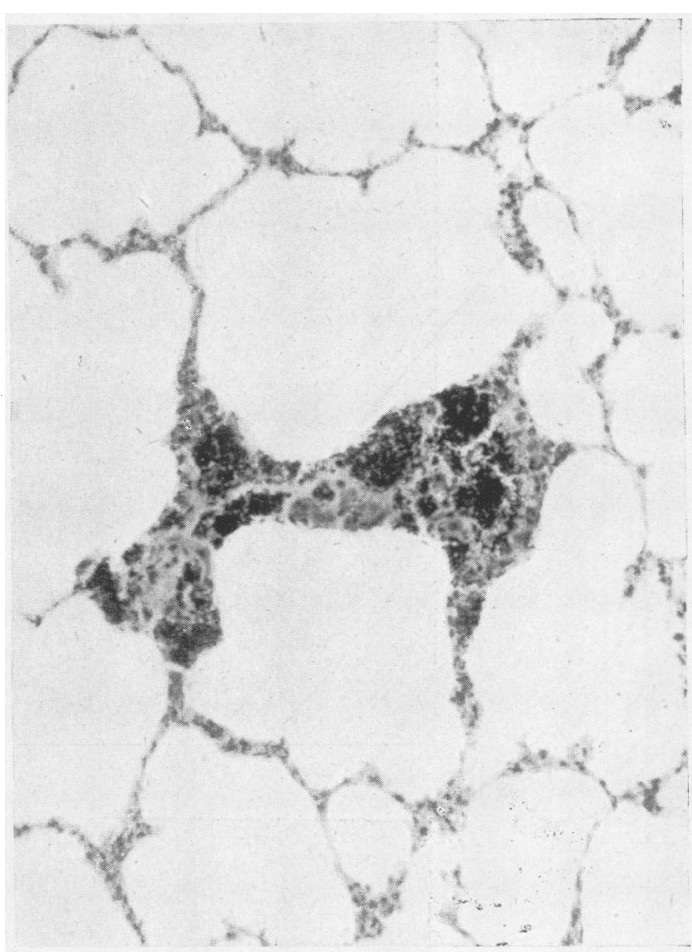

FIG. 2.

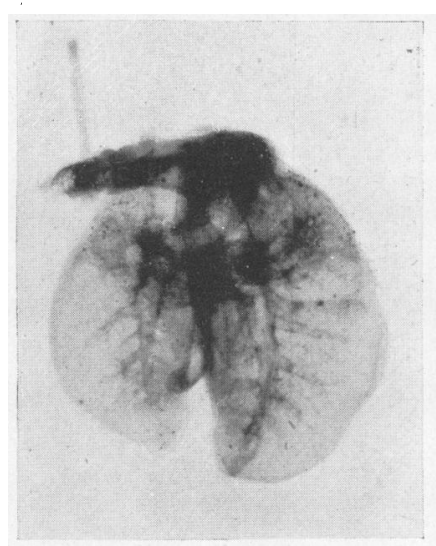

FIG. 4.

FIG. 1.-Aggregation of dust-filled phagocytes a short distance beneath the pleura. Hæmatoxylin and eosin $\times 190$.

Figs. 2 and 3.-Aggregates of dust-filled phagocytes within lung. Hæmatoxylin and eosin $\times 190$.

FIG. 4.-Radiograph of lungs, natural size. The heart was removed before photographing. 